\section{Evaluations for Determination of Optimum Shields in Nuclear Medicine}

\author{
Parvaresh R. ${ }^{1 \oplus}$, Jalili M. ${ }^{2 *}{ }^{\oplus}$, Haghparast A. ${ }^{3}$, Khoshgard K. ${ }^{3}$, \\ Eivazi M. T. ${ }^{3}$, Ghorbani M. ${ }^{4}$
}

\begin{abstract}
Background: ${ }^{131}$ I source is widely used in the treatment of hyperthyroidism and thyroid cancers. ${ }^{131} \mathrm{I}$ emits both beta and gamma-rays. Radiation protection is considered for gamma rays emitted by ${ }^{131} \mathrm{I}$. It seems no special shield against ${ }^{131} \mathrm{I}$ source to be designed.
\end{abstract}

Objective: This research aims to evaluate determination of optimum shields in nuclear medicine against ${ }^{99} \mathrm{Tc}^{\mathrm{m}}$ and ${ }^{131} \mathrm{I}$ sources by dosimetric method. Additionally, Monte Carlo simulation was used to find the optimum thickness of lead for protection against ${ }^{131}$ I source.

Material and Methods: This is an experimental research in the field of radiation protection. A calibrated model of GraetzX5C Plus dosimeter was used to measure exposure rates passing through the shields. The efficiency of the shields was evaluated against ${ }^{99} \mathrm{Tc}^{\mathrm{m}}$ and ${ }^{131} \mathrm{I}$. Furthermore, Monte Carlo simulation was used to find the optimum thickness of lead for protection against ${ }^{131}$ I source.

Results: The findings of the dosimetric method show that the minimum and maximum efficiencies obtained by the lead apron with lead equivalent thickness of $0.25 \mathrm{~mm}$ and the syringe holder shields with thickness of $0.5 \mathrm{~mm}$ lead were $50.86 \%$ and $99.50 \%$, respectively. The results of the simulations show that the minimum and maximum efficiencies obtained by lead thicknesses of $1 \mathrm{~mm}$ and $43 \mathrm{~mm}$ were $19.36 \%$ and $99.79 \%$, respectively.

Conclusion: The optimum shields against ${ }^{99} \mathrm{Tc}^{\mathrm{m}}$ are the syringe holder shield, the tungsten syringe shield, and the lead partition, respectively. Furthermore, based on simulations, the thicknesses of $11-28 \mathrm{~mm}$ of lead with efficiencies between $90.6 \%$ to $99 \%$ are suggested as the optimum thicknesses to protect against ${ }^{131} \mathrm{I}$ source.

Citation: Parvaresh R, Jalili M, Haghparast A, Khoshgard K, Eivazi MT, Ghorbani M. Evaluations for Determination of Optimum Shields in Citear Medicine. J Biomed Phys Eng. 2020;10(5):651-658. doi: 10.31661/jbpe.v0i0.1118
Nuclean

\section{Keywords}

Nuclear Medicine; Shield; Efficiency; Dosimetry; Monte Carlo Simulation; lodine-131; ${ }^{99} \mathrm{TC}^{\mathrm{m}}$

\section{Introduction}



any radionuclides are used in nuclear medicine with the aim of diagnosis and treatment of diseases [1]. The common radionuclides, which are used for diagnosis of diseases in nuclear medicine, are gamma emitters [2]. Radionuclides are significant sources of radiation and increase the risk of carcinogenic effects to personnel, patients and public [3]. In nuclear medicine, the main concern is safety of personnel against radiation [4]. It is a fact that ionizing radiation may cause genetic and carcinogenic effects [5]. There is much concern re-
${ }^{1} \mathrm{MSc}$, Medical Physics

Department, Faculty of

Medicine, Kermanshah

University of Medical

Sciences, Kermanshah,

Iran

${ }^{2} \mathrm{MD}$, Nuclear Medicine

Department, Imam Reza

Hospital, Kermanshah

University of Medical

Sciences, Kermanshah,

Iran

${ }^{3} \mathrm{PhD}$, Medical Physics

Department, Faculty of

Medicine, Kermanshah

University of Medical

Sciences, Kermanshah,

Iran

${ }^{4} \mathrm{PhD}$, Biomedical En-

gineering and Medical

Physics Department,

Faculty of Medicine,

Shahid Beheshti Univer-

sity of Medical Sciences,

Tehran, Iran

*Corresponding author:

M. Jalili

Nuclear Medicine De-

partment, Imam Reza

Hospital, Kermanshah

University of Medical Sci-

ences, Shahid Shiroodi

Boulevard, University

Street, Kermanshah, Iran

E-mail: dr.mahmood.

jalili@gmail.com

Received: 20 January 2019

Accepted: 4 March 2019 
garding to radiation protection of personnel, who are exposed to high energy gamma-rays emitted from radionuclides used in nuclear medicine.

The most common radionuclides, which are applied in nuclear medicine, are ${ }^{99} \mathrm{Tc}^{\mathrm{m}}$ and ${ }^{131} \mathrm{I}$ utilized for diagnostic and treatment of diseases $[2,6] .{ }^{131} \mathrm{I}$ emits both beta and gamma-rays. Beta-rays, which are applied for treatment purposes, are entirely absorbed by the patient's body [7]. Therefore, radiation protection is considered for gamma rays emitted by ${ }^{131} \mathrm{I}$.

${ }^{131}$ I source emits spectrum of gamma-rays as: $364 \mathrm{keV}(82 \%), 637 \mathrm{keV}(7 \%), 284 \mathrm{keV}$ $(6 \%), 80 \mathrm{keV}(3 \%)$ and $723 \mathrm{keV}(2 \%)$ [7]. In addition, ${ }^{99} \mathrm{Tc}^{\mathrm{m}}$ emits monoenergetic gamma photons with $140 \mathrm{keV}$ energy [8]. For years, shields, which are made of lead, were applied for radiation protection in radiation departments of hospitals [7]. Additionally, implementation of as low as reasonably achievable (ALARA) principle is needed to minimize the radiation to personnel and public in all of radiation departments [9].

International Commission on Radiological Protection (ICRP) recommends that application of lead apron is useful against ${ }^{99} \mathrm{Tc}^{\mathrm{m}}$ when personnel are exposed to high dose radiation, but it should not be used for protection against ${ }^{131}$ I because it does not provide a reasonable protection in this case [10].

A few studies have been performed to evaluate various shields in nuclear medicine. In fact, this study aims to determine the optimum shields against ${ }^{99} \mathrm{Tc}^{\mathrm{m}}$ and ${ }^{131} \mathrm{I}$ sources and an optimum thickness of lead shielding is suggested against ${ }^{131} \mathrm{I}$, as well.

\section{Material and Methods}

This an experimental study consists of two steps:

- The first step is evaluation of the efficiency of shields against ${ }^{99} \mathrm{Tc}^{\mathrm{m}}$ source by dosimetric method and lead partition as the only shield used against ${ }^{131} \mathrm{I}$.

- The second step is finding an optimum thickness of lead against ${ }^{131}$ I source by simulation method.

First step: evaluation of the efficiency of shields against ${ }^{99} \mathrm{Tc}^{\mathrm{m}}$ and ${ }^{131} \mathrm{I}$ sources

In the dosimetric set-up, a calibrated model of GraetzX5C Plus dosimeter (made in Germany by Graetz Strahlungsme $\beta$ technik Company) with reading range between 0.01-1000 $\mu \mathrm{Sv} / \mathrm{h}$, was used to measure the exposure rate passing through the evaluated shields in nuclear medicine. The dosimeter was calibrated by Secondary Standards Dosimetry Laboratory (SSDL) Karaj, Iran dependent on Atomic Energy Organization of Iran. In the dosimetric set-up, a plastic syringe containing $1 \mathrm{mCi}$ of ${ }^{99} \mathrm{Tc}^{\mathrm{m}}$ and/or ${ }^{131} \mathrm{I}$ hanging from a stand was considered as the source. A dose calibrator (Model of Initial Calibrated Blank (ICB) made in the United States by Alfa Aesar Company) was applied to measure the activities of the sources.

The applied shields were lead aprons with lead equivalent thicknesses of 0.25 and 0.5 $\mathrm{mm}$, a $0.5 \mathrm{~mm}$ thickness lead thyroid shield, a $3 \mathrm{~mm}$ thickness lead partition and a $2 \mathrm{~mm}$ thickness tungsten syringe shield and a syringe holder shield. The syringe holder shield was made up of lead shielding encased in steel with thickness of lead shielding $0.5 \mathrm{~mm}$ lead [11].

The dosimeter was placed at distance of 50 $\mathrm{cm}$ from the source in the horizontal direction and the reading of the dosimeter was recorded. Then each of the mentioned shields was hung from a stand while the dosimeter was placed behind the shields at distance of $50 \mathrm{~cm}$ from the source (Figure 1). The dosimeter reading was recorded again. In each case, the dosimetry was read three times in duration of 30 seconds in the nuclear medicine department. This time was selected since the personnel normally are exposed about 120 seconds from ${ }^{99} \mathrm{Tc}^{\mathrm{m}}$ and/or ${ }^{131} \mathrm{I}$ source at distance of $50 \mathrm{~cm}$ from the source. The average of the readings 
(a)


Figure 1: The set-up used in the dosimetric method; without shield (a); and with shield (b). This figure is schematic and not based on a real scale.

was considered as the reading of the dosimeter. The efficiency was calculated through the following equation:

$$
\text { Efficiency }(\%)=100 \times\left(I_{0}-I / I_{0}\right)
$$

The difference in this case is that herein $I$ and $I_{0}$ are dosimeter readings per unit time $(\mu \mathrm{Sv} / \mathrm{h})$ with and without shielding, respectively. The measured dose rates were less than the legal dose (20 mSv/yr) [12] for the radiation workers.

Lead partition is the only applied shield in nuclear medicine against high-energy gamma rays emitted by ${ }^{131} \mathrm{I}(82 \%, 364 \mathrm{keV})$. Therefore, in this study, the efficiency of lead partition was evaluated against ${ }^{131} \mathrm{I}$. After dosimetry for the shields, the simulations were conducted to find an optimum thickness of lead in order to protect against ${ }^{131} \mathrm{I}$.

Second step: Simulation to find an optimum thickness of lead against ${ }^{131}$ I source

In this study, simulation was used to find an optimum thickness of lead against ${ }^{131}$ I source. In the simulations, MCNPX Monte Carlo code (version 2.4.0) was used to simulate the interactions of photons with the lead shield. A server computer with 7-core $1.7 \mathrm{GHz}$ Intel mobile processor and 16.0 GB Random Access Memory (RAM) carried out the simulations.

In this set-up of simulation, a spherical ${ }^{131} \mathrm{I}$ source was simulated with $0.2 \mathrm{~mm}$ radius, emitting gamma-rays spectrum of: $364 \mathrm{keV}$ (82\%), $637 \mathrm{keV}(7 \%), 284 \mathrm{keV}(6 \%), 80 \mathrm{keV}$ (3\%) and $723 \mathrm{keV}(2 \%)$ [7]. A cylindrical dosimeter containing air with $1 \mathrm{~cm}$ radius and 1 $\mathrm{cm}$ height was also simulated at distance of 50 $\mathrm{cm}$ from the ${ }^{131}$ I source. An air environment was considered surrounding the dosimeter and the source (Figure 2). In the program of the simulation, a sheet of lead and/ or air with dimensions of $50 \mathrm{~cm} \times 30 \mathrm{~cm}$ and thickness of $0.1 \mathrm{~cm}$ was also simulated. The dimensions were determined optional (Figure 2).

F6 tally was used to calculate the energy deposited per unit mass $(\mathrm{MeV} / \mathrm{g})$ inside the dosimeter. In each of the simulations, the number of transported photons was $1.4 \times 10^{8}$. The energy cut-off for photons was defined to be 10 $\mathrm{keV}$. 


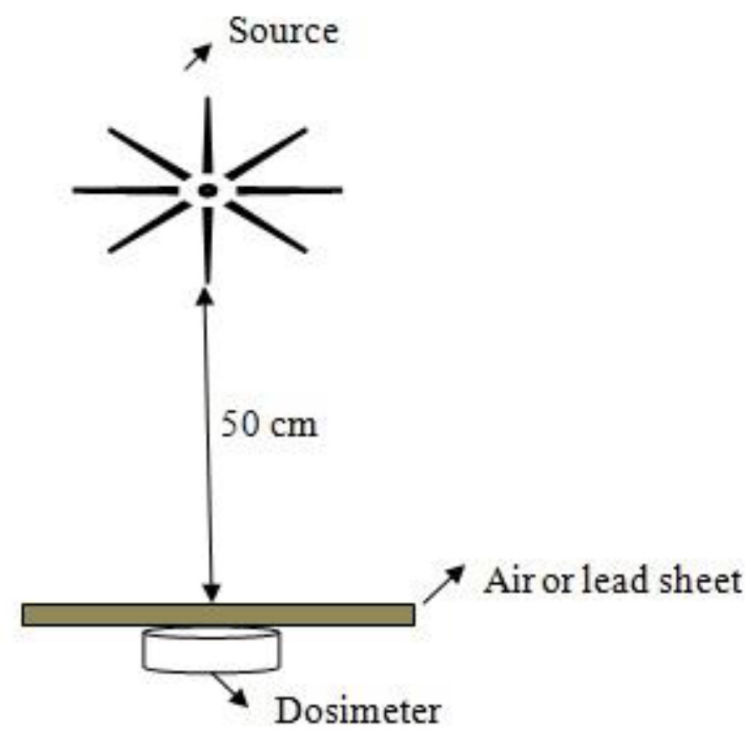

Figure 2: The set-up used in the simulation method. This figure is schematic and not based on a real scale.

Initially, a lead sheet was simulated with thickness of $0.1 \mathrm{~cm}$. Then its efficiency was calculated through the equation (1). In the next simulation, the thickness of the lead sheet then increased with $0.1 \mathrm{~cm}$ intervals. This method was followed to obtain the highest efficiency for the lead sheet against gamma-rays spec- trum emitted by the ${ }^{131}$ I source. Based on the MCNPX manual, the acceptable criterion for a simulation is that the uncertainty of the calculation is less than $5.0 \%$ [13]. In each simulation, type a uncertainty was between $1-4 \%$.

\section{Results}

Figure 3 shows the efficiencies of the used shields against ${ }^{99} \mathrm{Tc}^{\mathrm{m}}$ source in nuclear medicine. The minimum and maximum efficiencies were obtained from the lead apron with lead equivalent thickness of $0.25 \mathrm{~mm}$ and the syringe holder shields with lead shielding of $0.5 \mathrm{~mm}$ lead encased in steel were $50.86 \%$ and $99.5 \%$, respectively.

Figure 4 shows the efficiency of the lead partition with thickness of $3 \mathrm{~mm}$ against ${ }^{99} \mathrm{Tc}^{\mathrm{m}}$ and ${ }^{131}$ I sources. The efficiency of the lead partition was obtained $95.5 \%$ and $66.5 \%$ for ${ }^{99} \mathrm{Tc}^{\mathrm{m}}$ and ${ }^{131}$ I sources, respectively.

Figure 5 illustrates the efficiency obtained by the simulated lead shields with lead thicknesses of 1-44 mm. The minimum and maximum efficiencies obtained by lead thicknesses of 1 and $43 \mathrm{~mm}$ are $19.36 \%$ and $99.79 \%$, respectively.

\section{Discussion}

In this study, efficiencies were obtained for

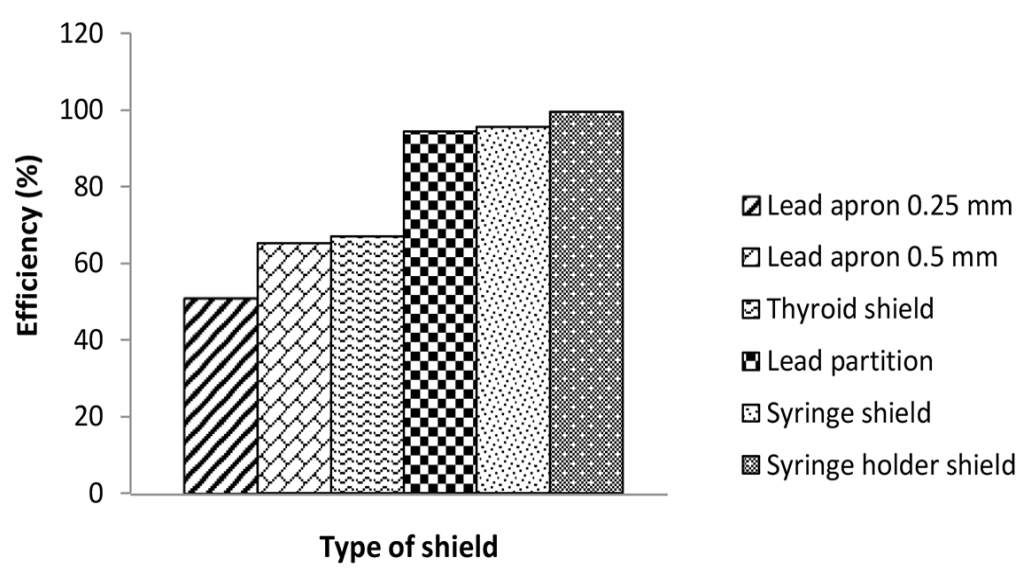

Figure 3: The efficiency obtained for the nuclear medicine shields against ${ }^{99} \mathrm{Tc}^{\mathrm{m}}$ source by the dosimetric method. 
nuclear medicine shields against $140 \mathrm{keV}$ gamma rays emitted by ${ }^{99} \mathrm{Tc}^{\mathrm{m}}$ (Figure 3), and efficiency of lead partition was obtained against ${ }^{131}$ I source by dosimetric method (Figure 4). Additionally, simulations were carried out to find an optimum thickness of lead material as a shielding against gamma-rays spectrum emitted by ${ }^{131}$ I (Figure 5).

Based on the dosimetric method of the shields against the ${ }^{99} \mathrm{Tc}^{\mathrm{m}}$ source, the shields with more thicknesses provide higher efficiencies against ${ }^{99} \mathrm{Tc}^{\mathrm{m}}$. This is due to higher number of photons interactions with atoms of the shield. Photons lose much energy and finally are stopped in the shield (Figure 3). In the case of lead apron with lead equivalent thicknesses of 0.25 and $0.5 \mathrm{~mm}$ and thyroid shield with lead equivalent thickness of $0.5 \mathrm{~mm}$, the

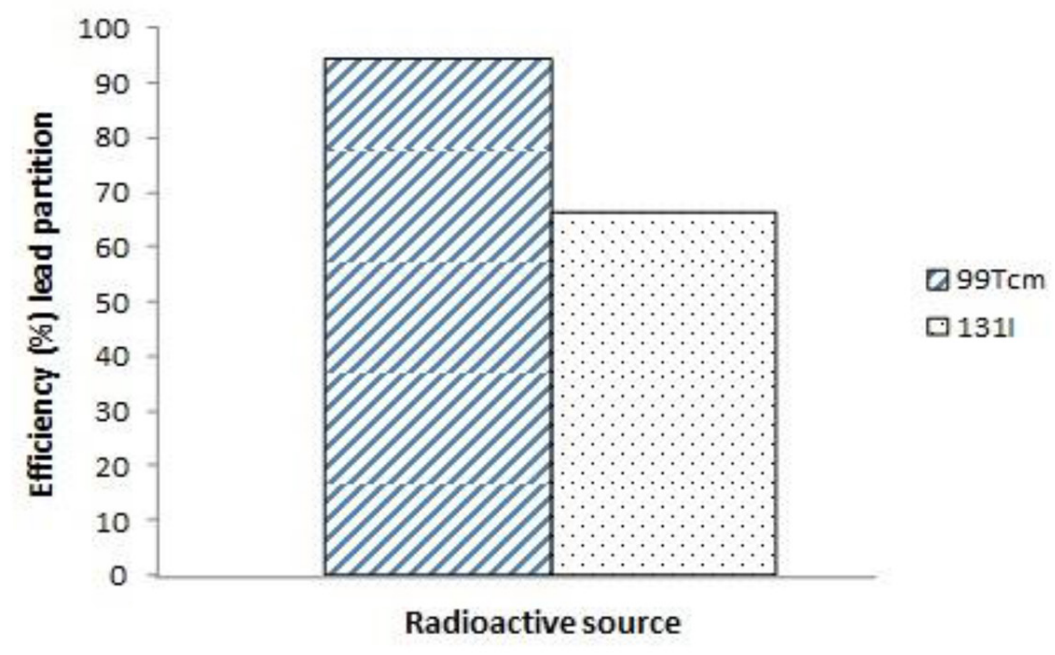

Figure 4: The efficiency obtained for the lead partition against ${ }^{99} \mathrm{Tc}^{\mathrm{m}}$ and ${ }^{131} \mathrm{I}$ sources by the dosimetric method.

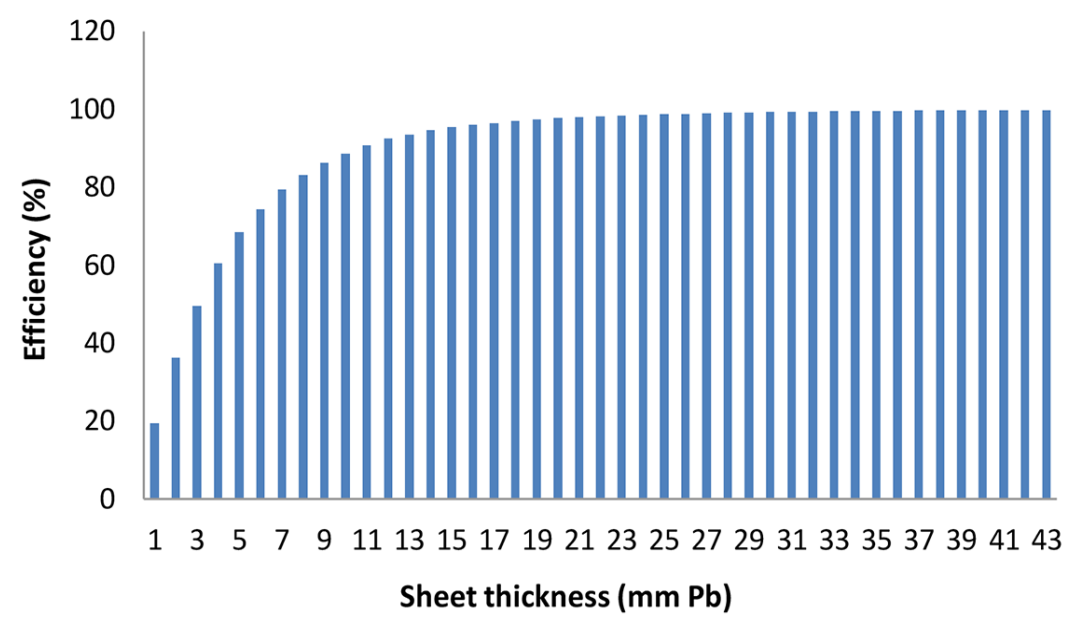

Figure 5: The efficiency obtained for the simulated lead shield with various thicknesses against the ${ }^{131}$ I source by the simulation method. 
results show that they provide efficiencies less than $70 \%$ (Figure 3). This is because of the predominance of Compton scattering at $140 \mathrm{keV}$ photon energy emitted by the ${ }^{99} \mathrm{Tc}^{\mathrm{m}}$. Compton scattering is independent to atomic number of shield but it is dependent to shieldmaterial density. Material shield is lead with relative density $\left(11.34 \mathrm{~g} / \mathrm{cm}^{3}\right)$, which is less than high-density materials such as tungsten with density $19.25 \mathrm{~g} / \mathrm{cm}^{3}$. Thus, at high energy (more than $100 \mathrm{keV}$ ) for obtaining the higher efficiency, high- or low-density material shield with less thickness and/or more thickness can be used, respectively. Therefore, it seems that the lead aprons and the thyroid shield are not optimum shields against a ${ }^{99} \mathrm{Tc}^{\mathrm{m}}$ source due to lower density of lead and less thickness. This indicates that studies should be carried out to find an optimum material for protective garment for nuclear medicine personnel against ${ }^{99} \mathrm{Tc}^{\mathrm{m}}$ source. Based on a previous study, an optimum material was achieved as the protective garment for nuclear medicine personnel against ${ }^{99} \mathrm{Tc}^{\mathrm{m}}$ source [14]. In a similar study, using dosimetric method, Young [15] showed that lead apron with lead equivalent thickness of $0.5 \mathrm{~mm}$ provides efficiency of $64.5 \%$ against ${ }^{99} \mathrm{Tc}^{\mathrm{m}}$ while in the current study, this was obtained $65 \%$. The result of the current study is in good agreement with Young's study with differences equal to $0.5 \%$. Furthermore, in a similar study, Ahmed's et al. [16] showed that the efficiency of lead apron with lead equivalent thickness of $0.5 \mathrm{~mm}$ was $82.7 \%$ for ${ }^{99} \mathrm{Tc}^{\mathrm{m}}$ source. The result of the current study is relatively in low agreement with study carried out by Ahmed with a difference equal to $17.7 \%$. It seems that this discrepancy is due to different situations used in these studies such as the types of dosimeters, exposure times and distances from the source. In study carried out by Ahmed et al., measurements were made by thermoluminescent dosimeter placed at $2 \mathrm{~cm}$ distance from ${ }^{99} \mathrm{Tc}^{\mathrm{m}}$ source with and without lead apron for durations of 49 to 57 minutes [16]. In the current study, measurements were made using a calibrated model of GraetzX5C Plus dosimeter and the dosimeter was placed at $50 \mathrm{~cm}$ distance from the ${ }^{99} \mathrm{Tc}^{\mathrm{m}}$ source with and without lead apron for duration of less than 1 minute in each dosimetric measurement.

In the case of shields such as lead partition, syringe shield and syringe holder shield, the results show that they provide efficiencies higher than $90 \%$ against ${ }^{99} \mathrm{Tc}^{\mathrm{m}}$ radionuclide (Figure 3 ). In the case of a lead partition, it provides high efficiency equal to $94.4 \%$ against ${ }^{99} \mathrm{Tc}^{\mathrm{m}}$ since high thickness of lead partition is seemly equal to $3 \mathrm{~mm}$ lead. At high thickness, interactions of high-energy photons with atoms of shield increased and more photons stopped at shield. Therefore, a lead partition with thickness of $3 \mathrm{~mm}$ is an optimum shield against ${ }^{99} \mathrm{Tc}^{\mathrm{m}}$ source. This is due to the predominance of Compton scattering at $140 \mathrm{keV}$ photon emitted by the ${ }^{99} \mathrm{Tc}^{\mathrm{m}}$. Compton scattering is dependent on density of material shield and independent on atomic number of shield. It is fact that at high-energy (more than 100 $\mathrm{keV}$ ) lead shield due to relatively low density should be used with high thickness to provide higher efficiency against ${ }^{99} \mathrm{Tc}^{\mathrm{m}}$.

In the case of the tungsten syringe shield, again due to the predominance of Compton scattering at $140 \mathrm{keV}$ energy, the tungsten syringe shield with a high density $\left(19.25 \mathrm{~g} / \mathrm{cm}^{3}\right)$ and thickness of $2 \mathrm{~mm}$ is the optimum shield to protect radiation worker's hands against gamma photons emitted by ${ }^{99} \mathrm{Tc}^{\mathrm{m}}$. In a similar study, Schürnbrand's et al. [17] showed that the continuous use of tungsten syringe shield could significantly reduce the dose of fingers tips from $60 \mathrm{rad} / \mathrm{y}$ to $2-3 \mathrm{rad} / \mathrm{y}$. The results of the current study are in agreement with the results obtained from study carried out by Schürnbrand et al. and only there is $1-2 \%$ difference.

In the case of the syringe holder shield, it provides the highest efficiency than other shields mentioned in this study against ${ }^{99} \mathrm{Tc}^{\mathrm{m}}$ source. This may be due to its special structure made up of lead shielding encased in steel with 
the shielding tapers from $0.5 \mathrm{~mm}$ lead [11]. In the other words, the high efficiency of syringe holder is due to the combination of lead and steel in a cylindrical shape. Furthermore, steel has some advantages such as absorption of high-energy photons, radiation shielding, and lower thermal conductivity [18]. There are uncertainties in the dosimetric method in this study, which may be due to radiation contaminations in the dosimeter. The type a uncertainties are low because the readings of dosimeter were very similar in repeated dosimetry for each shield.

The results of the dosimetric method against ${ }^{131}$ I source show that the lead partition does not provide any significant efficiency against gamma-rays (364 keV (82\%)) emitted by ${ }^{131} \mathrm{I}$ source, but this is not true regarding to the lead partition against $140 \mathrm{keV}$ gamma-rays emitted by the ${ }^{99} \mathrm{Tc}^{\mathrm{m}}$ source (Figure 4). It is as a result of predominance of Compton effect at high energy photons (364 keV) emitted by ${ }^{131} \mathrm{I}$. Compton scattering is dependent on density of material shield and independent on atomic number of shield. Furthermore, Lead is a material with relative density $\left(11.34 \mathrm{~g} / \mathrm{cm}^{3}\right)$ less than highdensity materials such as tungsten with density $19.25 \mathrm{~g} / \mathrm{cm}^{3}$. At high energy (more than $100 \mathrm{keV}$ ), lead shield with more thickness provides higher efficiency. It is concluded that lead partition with higher thicknesses should be applied for protection against a ${ }^{131}$ I source.

Therefore, in this study, Monte Carlo simulation was used to find the optimum thickness of lead shield against ${ }^{131}$ I source. The results of the simulations show that lead shields with thicknesses of 11-28 mm provide efficiency ranging from 90.6\%-99.0\% (Figure 5). At thicknesses higher than $28 \mathrm{~mm}$, efficiency slightly increased. For example, at thicknesses of $29-43 \mathrm{~mm}$, efficiency is ranging from 99.10 to $99.79 \%$. For ${ }^{131} \mathrm{I}$, it seems that higher thicknesses of lead provide higher efficiencies because lead has continuously increased mass attenuation coefficient at energies less than 1000 $\mathrm{keV}$. This is reasonable based on the diagram of mass attenuation coefficient for lead in energies less than $1000 \mathrm{keV}$ [19].

It is concluded that lead shields with thicknesses of 11-28 $\mathrm{mm}$ are optimum for ${ }^{131} \mathrm{I}$ source in nuclear medicine. Additional to high efficiency, the weight of shield is another important factor for designing the shield and its durable. Therefore, it seems that lead shield with thickness of $11 \mathrm{~mm}$ is optimum and can be applied to protect against high-energy gamma rays $(364 \mathrm{keV})$ emitted by ${ }^{131}$ I source in nuclear medicine. In a similar dosimetric study carried out by Deb's et al. [20] it was concluded that lead shield with lead equivalent thickness of $1.25 \mathrm{~mm}$ did not reduce the dose against ${ }^{131} \mathrm{I}$ source. In the present study, using simulation method, the efficiency of lead shield with thickness of $1 \mathrm{~mm}$ was obtained $19.36 \%$ against ${ }^{131}$ I source, which is a low level of efficiency. The result of this study is in agreement with the result of the study conducted by Deb's et al.

Based on the results of the current study, a lead shield with higher thickness is necessary to protect against the gamma rays by ${ }^{131} \mathrm{I}$ source and a higher thickness leads to a higher weight that is disadvantage. As a future study, it is suggested that this work is performed to find an optimum material as the protective garment against ${ }^{131}$ I source in nuclear medicine.

\section{Conclusion}

Lead partition, lead syringe and syringe holder shield provide efficiencies higher than $90 \%$, and they are optimum shields used routinely against $140 \mathrm{keV}$ gamma-rays emitted by ${ }^{99} \mathrm{Tc}^{\mathrm{m}}$ source in nuclear medicine.

In the case of ${ }^{131}$ I source, the available lead partition with lead equivalent thickness of 3 $\mathrm{mm}$ does not provide significant efficiency. It seems that lead shields with thicknesses of 11$28 \mathrm{~mm}$ provide the optimum efficiencies ranging from $90.6 \%$ to $99.0 \%$ against ${ }^{131}$ I source.

\section{Acknowledgment}

This study was performed with financial 
support of Student Research Committee, Kermanshah University of Medical Sciences. The authors would like to thank the Clinical Research Development Center of Imam Reza Hospital for Consulting Services.

\section{Conflict of Interest}

None

\section{References}

1. Fahey FH, Goodkind A, Treves ST, Grant FD. Nuclear medicine and radiation protection. J Radiol Nurs. 2016;35:5-11.

2. Vucina J. Technetium-99m production for use in nuclear medicine. Med Pregl. 2000;53:631-4.

3. Willegaignon J, Malvestiti LF, Guimaraes MI, Sapienza MT, Endo IS, Neto GC, et al. 131I effective half-life (Teff) for patients with thyroid cancer. Health Phys. 2006;91:119-22. doi: 10.1097/01. HP.0000202232.98823.87. PubMed PMID: 16832192.

4. Bolus NE. Review of common occupational hazards and safety concerns for nuclear medicine technologists. J Nucl Med Technol. 2008;36:117. doi: 10.2967/jnmt.107.043869. PubMed PMID: 18287195.

5. Oyar 0, Kislalioglu A. How protective are the lead aprons we use against ionizing radiation? Diagn Interv Radiol. 2012;18:147-52. doi: 10.4261/13053825.DIR.4526-11.1. PubMed PMID: 22020951.

6 . Thompson MA. Radiation safety precautions in the management of the hospitalized (131)I therapy patient. J Nucl Med Technol. 2001;29:61-6. PubMed PMID: 11376097.

7. Wyszomirska A. Iodine-131 for therapy of thyroid diseases. Physical and biological basis. Nucl Med Rev Cent East Eur. 2012;15:120-3. PubMed PMID: 22936505.

8. Dokic DD. Technetium-99m radiopharmaceuticals for in vivo diagnostics. Med Pregl. 2005;58:180-4. doi: 10.2298/mpns0504180d. PubMed PMID: 16526218.

9. Bushberg JT, Seibert JA, Leidholdt EM, Boone JM. The essential physics of medical imaging, 3rd Edition. North American: Lippincott Williams \& Wilkins; 2011.

10. Australian Radiation Protection and Nuclear Safety Agency. Safety guide radiation protection in nuclear medicine, No.14.2. [Accessed Feb 2017]. Available from: https://www.arpansa.gov.au/sites/default/files/ legacy/pubs/rps/rps14_2.pdf.

11. Radiation product design, Inc. Lead shielded syringe holder. 2017. [Accessed March 2017]. Available at: http://www.rpdinc.com/lead-shielded-syringe-holder-4485.html.

12. Sylvain I, Bok B. Radiation exposure in nuclear medicine: real-time measurement. Braz Arch Biol Technol. 2002;45:111-4. doi: 1590/S151689132002000500015.

13. Shultis JK, Faw RE. Mechanical and Nuclear Engineering, Kansas State University, Manhattan. [Accessed Nov. 2016]. Available at: http://www. bl831. als.lbl.gov/ mcfuser/publications/MCNP/MCNP.

14. Parvaresh R, Haghparast $A$, Khoshgard $K$, Jalili $M$, Eivazi MT, Ghorbani M. An Investigation to Determine an Optimum Protective Garment Material in Nuclear Medicine. J Biomed Phys Eng. 2018;8:38192. PubMed PMID: 30568928. PubMed PMCID: PMC6280121.

15. Young AM. Dose rates in nuclear medicine and the effectiveness of lead aprons: updating the department's knowledge on old and new procedures. Nucl Med Commun. 2013;34:254-64. doi: 10.1097/MNM.0b013e32835c91d5. PubMed PMID: 23353888.

16. Ahmed S, Zimmer A, McDonald N, Spies S. The effectiveness of lead aprons in reducing radiation exposures from specific radionuclides. J Nucl Med. 2007;48:470P-P.

17. Schürnbrand $P$, Schicha $H$, Thal $H$, Emrich D. External radiation exposure of personnel working with $99 \mathrm{~m}$ Technetium. Eur J Nucl Med. 1982;7:237-9. doi: 10.1007/bf00256472.

18. Smith B, Szyniszewski S, Hajjar J, Schafer B, Arwade S. Steel foam for structures: A review of applications, manufacturing and material properties. Journal of Constructional Steel Research. 2012;71:1-10. doi: 10.1016/j.jcsr.2011.10.028.

19. Hubbell JH, Seltzer SM. X-ray mass attenuation coefficients. Standard reference data program of NIST. [Accessed May 2017]. Available from: http://physics. nist.gov/PhysRefData/XrayMassCoef/ElemTab/z82. html.

20. Deb P, Jamison R, Mong L, U P. An evaluation of the shielding effectiveness of lead aprons used in clinics for protection against ionising radiation from novel radioisotopes. Radiation Protection Dosimetry. 2015;165:443-7. doi: 10.1093/rpd/ncv065. 